\title{
Analysis of Dissolved and Colloidal Substances in Old Corrugated Containers' Whitewater and Dissolved Substances' Impact on Colloidal Substances' Stability
}

Hui Liu, ${ }^{\text {a,b }}$ Meiling Li, ${ }^{\text {a,b }}$ Kaili Zhu, ${ }^{\text {a,b }}$ Haitong Ma, ${ }^{\text {a,b }}$ Yueru Wu, ${ }^{\text {a,b }}$ Zhiwei Wang, ,a,c,* and Shuangfei Wang a,b

The physicochemical properties of dissolved and colloidal substances (DCS) in the old corrugated containers' (OCC) whitewater were studied. Then, the colloidal substances (CS) were separated from dissolved substances (DS) and the effect of inorganic salts on the stability of CS (not DCS) was studied for the first time. The results showed that many DCS aggregated and attached to the fiber surface when pulping. The primary sources were resin, lignin, adhesives, coating fixatives, and fillers. The colloidal stability of DCS and solids of whitewater differed because the DCS contained less filler. Both $\mathrm{Ca}^{2+}$ and $\mathrm{Na}^{+}$can affect the stability of $\mathrm{CS}$, but $\mathrm{Ca}^{2+}$ led to more CS instability and aggregated into larger flocculent precipitates. The surprising discovery in the experiment was that when $\mathrm{Ca}^{2+}$ and $\mathrm{Na}^{+}$were added together, the instability degree of the system was between the addition of $\mathrm{Ca}^{2+}$ and $\mathrm{Na}^{+}$alone. $\mathrm{Ca}^{2+}$ played a dominant role in affecting the stability of $\mathrm{CS}$, and $\mathrm{Na}^{+}$competed for adsorption sites.

Keywords: OCC whitewater; Dissolved and colloidal substances; Stability; Instability

Contact information: a: School of Light Industry and Food Engineering, Guangxi University, Guangxi, P. R. China; b: Guangxi Key Laboratory of Clean Pulp \& Papermaking and Pollution Control, Guangxi, P.

R. China; c: Key Laboratory of Pulp and Paper Science \& Technology of Ministry of Education/Shandong Province, Qilu University of Technology (Shandong Academy of Sciences), Jinan, 250353, China;

* Corresponding author: wangzhiwei@gxu.edu.cn

\section{INTRODUCTION}

Wastepaper recycling is beneficial to saving resources of wood, protecting the environment, and reducing production costs. Old corrugated containers (OCC) are one crucial component of the wastepaper industry (Monte et al. 2009; Li et al. 2018). When the OCC are reused, many foreign materials are introduced to system, with some of them becoming present in whitewater as dissolved and colloidal substances (DCS) (Liang et al. 2018). The composition of DCS, which mainly comes from pulp, fillers, recycled water, and the chemicals added during the papermaking processes, is complex (Hubbe et al. 2012; Wang 2013). It has been found that DCS keeps accumulating with whitewater and might interfere in the wet-chemical environment of pulp and papermaking (Rundlof et al. 2000, 2002; Nurmi et al. 2004). Most of the colloids in DCS have carboxyl groups and are negatively charged. The DCS will preferentially react with cationic additives, reducing the effectiveness of the cationic additives and increasing the required dosage, simultaneously increasing costs, and further deteriorating the wet-end of pulp and papermaking. Second, with the environment changing suddenly, it will lead to the instability of the whitewater system from a large amount of DCS flocculates and formation of more harmful stickies, resulting in mesh clogging, eventually affecting the operation of the paper machine and the 
quality of the paper products (Blanco et al. 1996; Monte et al. 2004; Blanco Suárez et al. 2007).

Previous studies mainly have focused on the characteristics of DCS as a whole. For example, Liang et al. (2018) found that with the increase of water recycling times, the accumulation of DCS increased linearly and the concentration of inorganic ions also increased. $\mathrm{Xu}$ et al. (2004) concluded that in a closed system, any reduction in the water consumption of the paper machine would increase dissolved and colloidal substance. Wang (2014) reported that DCS in whitewater mainly came from agents, extraction content of fiber raw material was minimal. Few scholars have explored the effects of electrolytes on the stability of CS and the mechanism of DCS instability. Interestingly, cultural paper and old newspaper have been widely studied (Francis and Ouchi 2001; Zhang et al. 2007; Su et al. 2016). The OCC was researched less, as a critical component of recycled paper in the paper industry.

This experiment needed a large amount of wastewater, which was difficult to transport and store (Jiang et al. 2018). Therefore, simulated OCC whitewater was used to explore the influence of inorganic electrolyte on the stability of CS, and to determine the maximum concentration of inorganic electrolyte when DCS water was destabilized, to provide technical assistance to control the DCS of whitewater effectively.

\section{EXPERIMENTAL}

\section{Materials}

Preparation of simulated OCC whitewater

The OCC (Mei Ying Da, Shenzhen, China) was cut into $5 \times 5 \mathrm{~cm}$ pieces and stored in a sealed bag at room temperature for $24 \mathrm{~h}$ to balance the moisture. The pieces were beaten at $300 \mathrm{rpm}$ for $20 \mathrm{~min}$ at $10 \%$ pulp concentration in a high consistency pulp machine (Adirondack Machine Corporation, Hudson Falls, NY, USA) at $60{ }^{\circ} \mathrm{C}$. The pulp concentration was diluted to $2 \%$ with tap water and stirred at $60{ }^{\circ} \mathrm{C}$ for $1 \mathrm{~h}$. The pulp was then screened with a 200-mesh dynamic water filter (DDJ) under $800 \mathrm{rpm}$ stirring, and the liquid was filtered as OCC simulated whitewater (Jiang 2007; Chen et al. 2014).

\section{Separation of DCS and CS in simulated whitewater}

The OCC whitewater was centrifuged at $2000 \mathrm{rpm}$ for $20 \mathrm{~min}$. The solids of the whitewater were separated to obtain the supernatant as the DCS water. The DCS water was dialyzed with deionized water by a dialysis tube for $48 \mathrm{~h}$ (deionized water replaced every 4 h), then obtained the CS (Johnsen et al. 2004; Chen 2016).

\section{DCS stability test}

Different concentrations of $\mathrm{NaCl}, \mathrm{CaCl}_{2}$, and mixed solutions of them were prepared and preheated to $45^{\circ} \mathrm{C}$. The $\mathrm{NaCl}, \mathrm{CaCl}_{2}$, and mixed solution were added to 100 $\mathrm{mL} \mathrm{CS}$ water, stirred at $50 \mathrm{rpm}$ at $45^{\circ} \mathrm{C}$ for $30 \mathrm{~min}$. The zeta potential and the particle size of the CS were then tested. The supernatant was obtained at $2000 \mathrm{rpm}$ for $20 \mathrm{~min}$ and turbidity measured to analyze the influence of inorganic electrolyte on the stability of CS.

\section{Analytical Methods}

The cation demand (CD) was automatically titrated and measured using the PCD03 streaming current detector (Mutek, Filderstadt, Germany). The electrical conductivity 
of different water samples was measured using the DDSJ-308F conductivity measurement (Leici, Beijing, China). Turbidity was measured using the $2100 \mathrm{~N}$ Turbidimeter (Hach, Loveland, CO, USA). The zeta potential and particle size were measured using the Zetasize Nano-SZ90 Zeta potentiometer (Malvern, Westborough, MA, USA). The chemical oxygen demand (COD) was determined by the 5B-3B water quality analyzer (Lianhua, Shanghai, China). The simulated concentration of $\mathrm{Ca}^{2+}$ and $\mathrm{Na}^{+}$in whitewater was determined using the 700 Series ICP-OES inductively coupled plasma emission spectrometry (Agilent Technologies, Santa Clara, CA, USA). After the OCC was pulped under different conditions, the DCS appearance was studied by the scanning electron microscope (SEM) (F16502) (Phenom, Eindhoven, Holland). The material composition of DCS was analyzed by pyrolysis-gas chromatography-mass spectrometry-QP2010 Plus (Py-GC-MS) (Shimadzu, Kyoto, Japan) and determination of thermal stability by the STA 449F5 thermogravimetric analyzer (TG) (Netzsch, Selb, Germany) (Li 2005; Li et al. 2008; Sousa et al. 2018).

\section{RESULTS AND DISCUSSION}

\section{The Basic Properties of Simulated OCC Whitewater}

The $\mathrm{pH}$ of the simulated whitewater was 7.8. The basic characteristics of simulated OCC whitewater, DCS, and CS is shown in Table 1. The solid content, the ash content, and the CD value of DCS water decreased compared with the whitewater. This trend was because the fibers and filler of whitewater were removed, and the positive charge needed for carboxyl ionization on the fiber surface was reduced after centrifugal sedimentation, resulting in decreased solid content, ash content, and $C D$ values. The $C D$ value and turbidity of CS water were only slightly reduced, showing that CS plays a major role in the cationic demand of DCS. The decrease of turbidity indicated that the DCS turbidity was mainly contributed by CS (Nylund et al. 2007).

The COD content of whitewater was higher than that of DCS and CS water, but there was no remarkable difference between DCS and CS. This was because the fibers of whitewater were removed after centrifugal sedimentation, which provides the most COD of whitewater. The COD content of CS accounts for $79.7 \%$ of DCS.

Table 1. Basic Properties of OCC Whitewater

\begin{tabular}{|c|c|c|c|c|c|c|c|c|}
\hline \multirow{3}{*}{ Parameters } & \multicolumn{9}{|c|}{ Measurement Indicators } \\
\cline { 2 - 10 } & $\begin{array}{c}\text { Solid } \\
\text { Content }\end{array}$ & Ash & Turbidity & CD & Conductivity & COD & $\begin{array}{c}\text { Metal lon Content } \\
(\mathrm{mg} / \mathrm{L})\end{array}$ \\
\cline { 2 - 10 } & $\mathrm{g} / \mathrm{L}$ & $\mathrm{g} / \mathrm{L}$ & $\mathrm{NTU}$ & $\mu \mathrm{eq} / \mathrm{L}$ & $\mu \mathrm{s} / \mathrm{cm}$ & $\mathrm{mg} / \mathrm{L}$ & $\mathrm{Ca}^{2+}$ & $\mathrm{Na}^{+}$ \\
\hline Whitewater & 1.75 & 0.50 & 766 & 132 & 666 & $\begin{array}{c}1005 . \\
2\end{array}$ & 360.8 & 23.4 \\
\hline DCS & 1.2 & 0.31 & 38.1 & 99 & 610 & 154.8 & 204.03 & 8.39 \\
\hline CS & 0.65 & 0.13 & 25.5 & 79 & 20 & 123.4 & 10.456 & 2.951 \\
\hline
\end{tabular}

The conductivity of the DCS water was slightly lower than the whitewater. The conductivity of the CS water decreased remarkably after dialysis, indicating that DCS conductivity was mainly contributed by DS. Conductivity can be used to show the content of inorganic electrolytes. The main inorganic electrolytes in whitewater were $\mathrm{Ca}^{2+}$ and $\mathrm{Na}^{+}$ (Tang 2018), and the content of $\mathrm{Ca}^{2+}$ and $\mathrm{Na}^{+}$also decreased remarkably in CS after 
dialysis in Table 1. The materials removed by centrifugation were fillers and other materials, and most of the dissolved substances still existed in the DCS water. Inorganic electrolytes were almost removed after dialysis treatment, resulting in a sharp decline in the conductivity of CS.

\section{Basic Properties of DCS \\ SEM analysis}

The OCC was diluted with raw whitewater (Fig. 1a), DCS water (Fig. 1b), and distilled water (Fig. 1c) to make pulp. The micromorphology of the paper sheets with different water pulping was observed by SEM. Figure 1(a) shows whitewater OCC pulping. A great deal of adhesives flocculated to form large stickies on the fiber surface, and there were also some fillers that make it look messy. Figure 1(c) was relatively clean compared with Fig. 1(b), but there was some large flocculation, indicating that DCS flocculates into a larger stickie deposited on the fiber surface. Therefore, the stickies acted like the flocculant in Fig. 1(a). Thus, it can be said that DCS had a great influence on the system due to the occurrence of unstable flocculation and is a key factor in the study of whitewater stability.
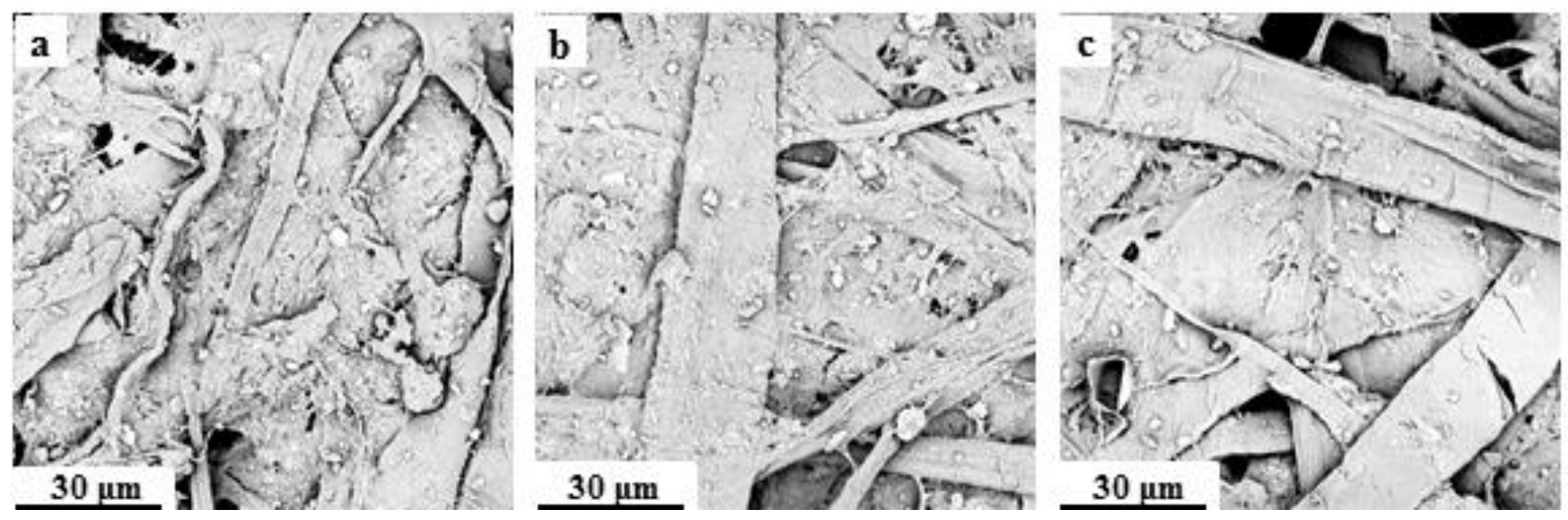

Fig. 1. SEM of OCC pulping under raw whitewater (a), DCS water (b), and distilled water (c)

\section{Speciation Analysis of CS}

The particle size of CS was fitted to a normal distribution with an average particle size of $483.3 \mathrm{~nm}$ (see Fig. 2). The particle size range was between 255 to $1000 \mathrm{~nm}$, and most samples were approximately $500 \mathrm{~nm}$. Because the DS was removed and the CS was fluffy, it led to an increased CS particle size. With the Dindal effect, a bright "pathway" could be observed in the colloid. Therefore, stability theory of colloidal system can still be introduced when discussing DCS stability (Wågberg et al. 2010).

\section{Composition Analysis of DCS by Py-GC-MS}

There were many polymer substances in the DCS component, which had a large molecular weight and could not be completely gasified. Therefore, they were decomposed into small substances and detected by Py-GC-MS. Then, its composition and possible sources were further speculated (Yuan et al. 2012). The results of the comparative spectrum are shown in Table 2. 


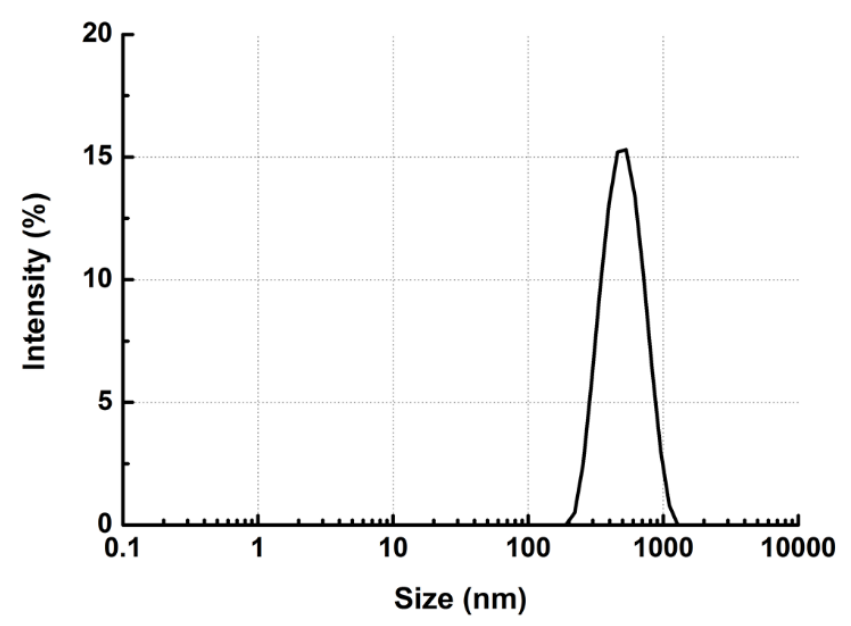

Fig. 2. Particle size distribution of CS

The DCS pyrolysis product contained abundant compounds, such as acetone, 2butanone, 2-methyl-2-cyclopentene-1-ketone, styrene, toluene, pentadecanoic acid (palmitate), and octadecanoic acid (stearic acid). From these different physical properties, possible sources can be roughly inferred. For example, 2-butylketone was an organic solvent for adhesives and coatings, 1,3-dimethoxybenzene, o-xylene, and 2-methyl phenol were products of lignin. Styrene was an important copolymer of styrene-butadiene-styrene (SBS) and styrene-styrene-styrene butadiene rubber (SBR) as well as a copolymer of latex coatings (Sarja 2007). Further, there were additional chain alkanes, alkene-type material, such as undecene, undecane, tridecane, pentadecene, and so on, which came from active agent or plasticizer. Hexadecanoic acid (palmitic acid) and octadecanoic acid (stearic acid) may have come from dispersants, surfactants, or in-pulp sizing agents in the papermaking process. Octadecanoic acid may also come from resins in the fibrous material itself. From the Table 2, it can be determined that DCS was complex and included the resin and lignin from wood, as well as the synthetic compounds of various adhesives, coating fixers, plasticizers, and other substances.

\section{TG Analysis of DCS}

The whitewater mainly contained DCS, fine fibers, fillers, and other substances, so thermogravimetric experiments were performed on DCS and whitewater to investigate its difference.
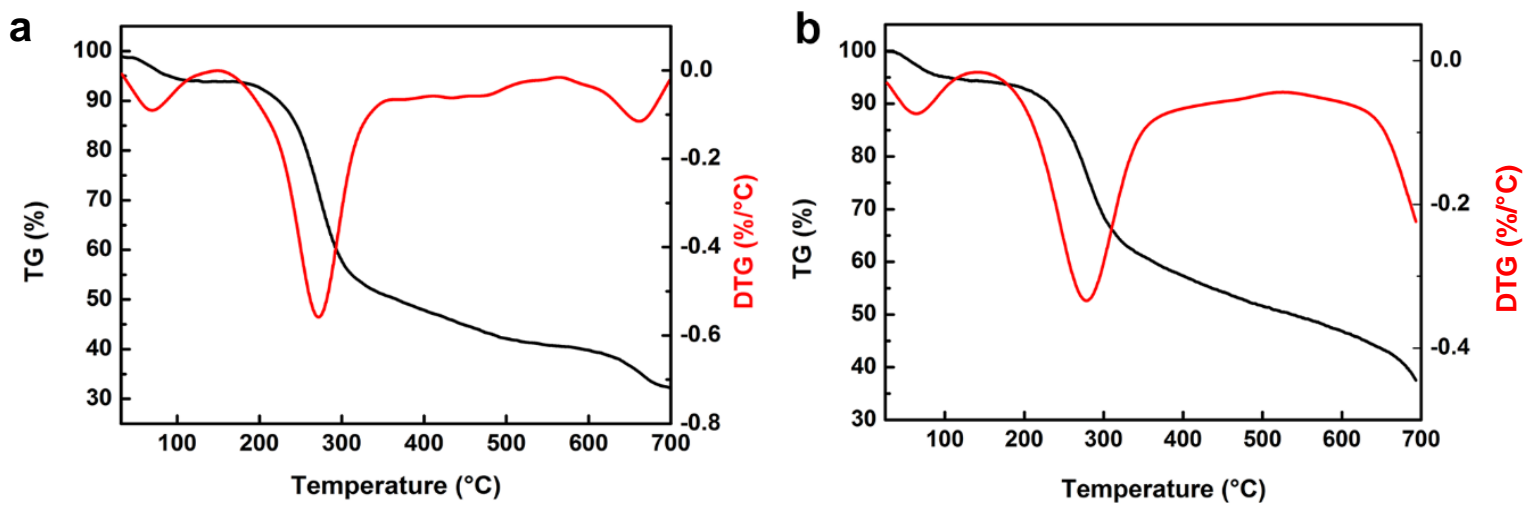

Fig. 3. TG and DTG curves of DCS (a) and whitewater (b) 
Table 2. Composition Analysis of DCS by Py-GC-MS

\begin{tabular}{|c|c|c|c|c|}
\hline $\begin{array}{l}\text { Time } \\
(\min )\end{array}$ & $\begin{array}{l}\text { Con- } \\
\text { tent }\end{array}$ & $\begin{array}{c}\text { Molecular } \\
\text { Formula }\end{array}$ & Name & Possible Source \\
\hline 1.901 & 11.36 & $\mathrm{CO}_{2}$ & Carbon dioxide & $\begin{array}{c}\text { Deep cracking of organic matter or } \\
\text { filler }\end{array}$ \\
\hline 3.226 & 6.89 & $\mathrm{C}_{4} \mathrm{H}_{8} \mathrm{O}$ & 2-Butanone & Adhesive \\
\hline 5.152 & 1.29 & $\mathrm{C}_{7} \mathrm{H}_{8}$ & Toluene & Deinking agent, defoaming agent, etc. \\
\hline 6.966 & 1.49 & $\mathrm{C}_{8} \mathrm{H}_{10} \mathrm{O}_{2}$ & $\begin{array}{c}1,3- \\
\text { Dimethoxybenzene }\end{array}$ & Lignin \\
\hline 7.123 & 0.93 & $\mathrm{C}_{8} \mathrm{H}_{10}$ & O-xylene & Lignin \\
\hline 7.539 & 5.31 & $\mathrm{C}_{8} \mathrm{H}_{8}$ & Styrene & Polystyrene, SBR, SBS, etc. \\
\hline 7.865 & 1.03 & $\mathrm{C}_{6} \mathrm{H}_{8} \mathrm{O}$ & $\begin{array}{l}\text { 3-Methyl-2- } \\
\text { cyclopenten-1-one }\end{array}$ & Scouring agent, activator, etc. \\
\hline 8.572 & 2.18 & $\mathrm{C}_{9} \mathrm{H}_{10}$ & Allylbenzene & $\begin{array}{c}\text { Sizing agent, drying agent and filter } \\
\text { agent for processing paper chemicals, } \\
\text { etc. }\end{array}$ \\
\hline 9.492 & 1.54 & $\mathrm{C}_{10} \mathrm{H}_{22}$ & Decane & Organic synthesis of resins \\
\hline 10.476 & 1.02 & $\mathrm{C}_{7} \mathrm{H}_{8} \mathrm{O}$ & 2-Methyl phenol & $\begin{array}{l}\text { Resins, dyes, antioxidants and } \\
\text { antimicrobial agents, etc. }\end{array}$ \\
\hline 10.981 & 1.42 & $\mathrm{C}_{11} \mathrm{H}_{22}$ & Hendecene & Surface-active agent \\
\hline 11.093 & 1.09 & $\mathrm{C}_{11} \mathrm{H}_{24}$ & Hendecane & Surface-active agent \\
\hline 12.273 & 1.27 & $\mathrm{C}_{12} \mathrm{H}_{24}$ & Dodecene & Surface-active agent, plasticizer, etc. \\
\hline 13.376 & 1.08 & $\mathrm{C}_{13} \mathrm{H}_{28}$ & Tridecane & Surface-active agent \\
\hline 14.165 & 1.83 & $\mathrm{C}_{14} \mathrm{H}_{28}$ & Pentadecene & Plasticizer, activator, etc. \\
\hline 14.912 & 1.62 & $\mathrm{C}_{15} \mathrm{H}_{30}$ & Toluene & Plasticizer, activator, etc. \\
\hline 15.575 & 2.13 & $\mathrm{C}_{16} \mathrm{H}_{34} \mathrm{O}$ & Hexadecanol & Detergent, plasticizer, etc. \\
\hline 16.619 & 1.07 & $\mathrm{C}_{14} \mathrm{H}_{28} \mathrm{O}$ & 2-Tetradecanone & Scouring agent, activator, etc. \\
\hline 17.635 & 2.89 & $\mathrm{C}_{16} \mathrm{H}_{32} \mathrm{O}_{2}$ & Pentadecanoic acid & Sizing agent, disperser, etc. \\
\hline 19.522 & 1.04 & $\mathrm{C}_{19} \mathrm{H}_{38} \mathrm{O}$ & Nonadecanone & Internal sizing agent, etc. \\
\hline 21.072 & 4.73 & $\mathrm{C}_{18} \mathrm{H}_{38} \mathrm{O}_{2}$ & Octadecanoic acid & Surface-active agent, disperser, etc. \\
\hline
\end{tabular}

It can be determined from Fig. 3 that there was a difference between DCS and whitewater, which was specifically manifested in the wide temperature range of the thermal cracking, with remarkable weight loss at 150 to $350{ }^{\circ} \mathrm{C}$ and $650{ }^{\circ} \mathrm{C}$ of DCS, and whitewater at 150 to $370{ }^{\circ} \mathrm{C}$ and 650 to $700{ }^{\circ} \mathrm{C}$. Figure 3 shows that the composition of DCS was complex and contained a variety of organic compounds, including low-molecular weight organics that were easy to be pyrolyzed at a wide and lower temperature $\left(150\right.$ to $\left.350{ }^{\circ} \mathrm{C}\right)$, and macromolecules, such as cellulose, of whitewater that were pyrolyzed near $370^{\circ} \mathrm{C}$. In Fig. 3(b), the weight loss at 150 to $370{ }^{\circ} \mathrm{C}$ may be from the pyrolysis of cellulose and DCS. The weight loss at $650{ }^{\circ} \mathrm{C}$ indicated that there were inorganic salt electrolytes in DCS (Miranda et al. 2006). There was a more remarkable weight loss in whitewater than DCS at 650 to $700{ }^{\circ} \mathrm{C}$, mainly due to the pyrolysis of calcium carbonate, the fillers that were not found in DCS (Wang et al. 2012).

\section{Electric Charge Characteristics of DCS}

The cationic demand and zeta potential are commonly used to evaluate the charge characteristics of DCS. The CD value can reflect the negative charge content of DCS while zeta potential can show the potential difference between the continuous phase of the colloid and the fluid stable layer attached to dispersed particles, which was closely related to the stability of DCS. The CS water was adjusted to different $\mathrm{pH}$ values and then the cationic demand and zeta potential of the solution were measured. The results are shown in Fig. 4. 

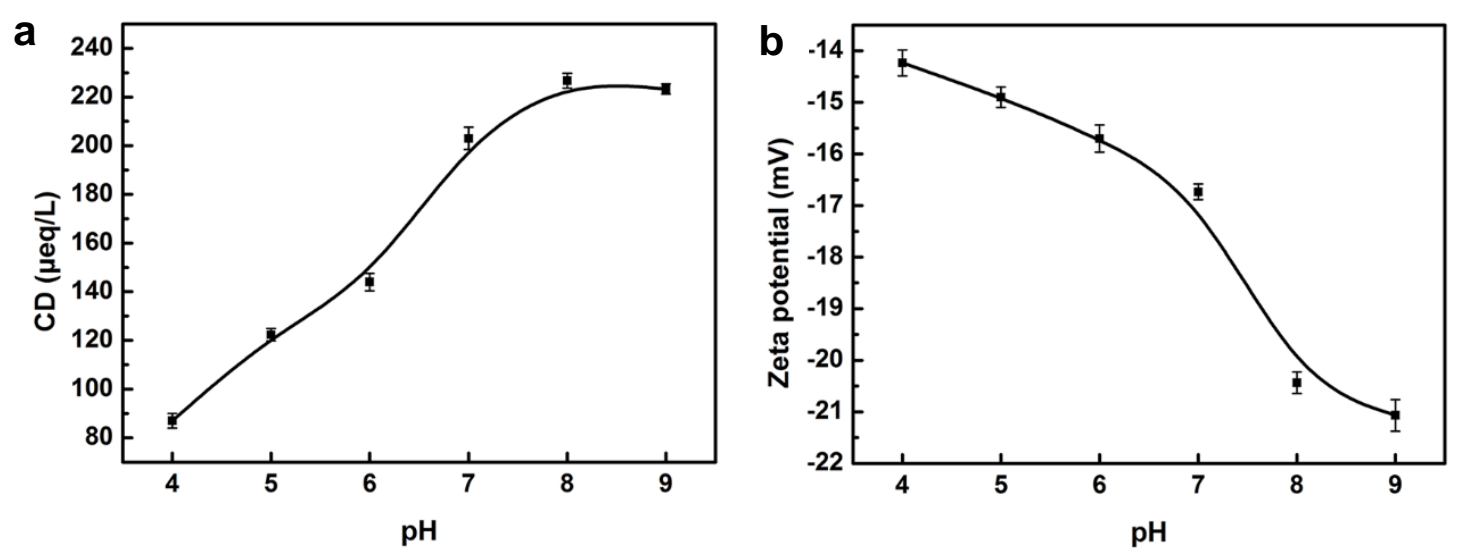

Fig. 4. Effects of different $\mathrm{pH}$ conditions of CS on CD (a) and Zeta potential (b)

As the $\mathrm{pH}$ value increased, the $\mathrm{CD}$ value and the absolute value of zeta potential kept increasing. This was attributed to the fact that CS mostly contained carboxyl groups and the ionization degree was affected by the $\mathrm{pH}$ value. Under the condition of low $\mathrm{pH}$ value, the carboxyl protonation degree was more protonated. With the increase of $\mathrm{pH}$ value, the carboxyl group was gradually dissociated into carboxylate anions, which increased the amount of negative charge carried by CS, increasing the CD value. At the same time, the increase of carboxyl ionization degree enhanced the negative charge of colloidal particles in CS, so the absolute value of zeta potential increased and the system stability improved (McLean et al. 2005; Lee et al. 2012). However, when the $\mathrm{pH}$ value was 9, the CD value and zeta potential were stable due to the fixed colloid content in the CS water. This indicated that the charge characteristics of DCS were related to the number of colloids, and zeta potential and $\mathrm{CD}$ values did not always increase with the increase of $\mathrm{pH}$.

\section{Effect of Reaction Time}

Turbidity is caused by suspended solids (SS) and CS in the water. In the absence of SS, its value can indirectly represent the content of CS (Sundberg et al. 1993). The residual turbidity of the supernatant after centrifugation of the water was detected to reflect the content of CS.
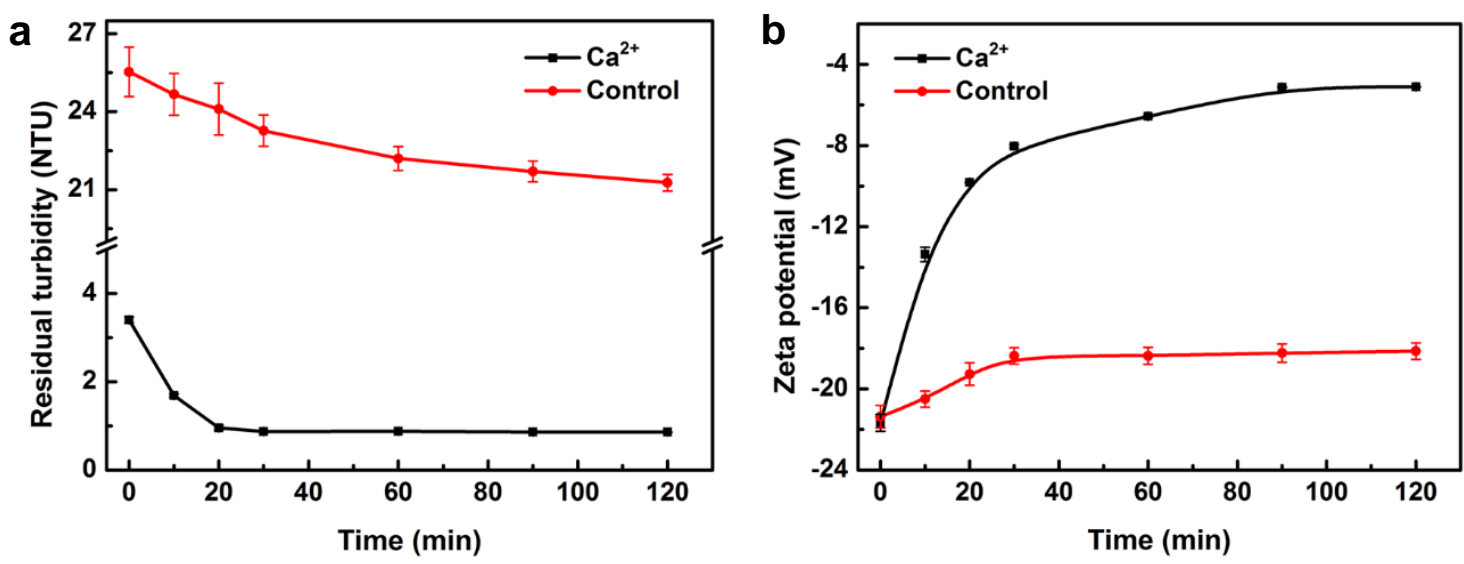

Fig. 5. Effects of $\mathrm{Ca}^{2+}$ addition at different times on residual turbidity of $\mathrm{CS}$ (a) and zeta potential (b) 
$\mathrm{Ca}^{2+}$ was added into the $\mathrm{CS}$ water at a concentration of $8 \mathrm{mmol} / \mathrm{L}$, the supernatant was centrifuged at $2000 \mathrm{rpm}$ for $20 \mathrm{~min}$. The effect of inorganic electrolyte on the stability of CS with time were tested by the change of turbidity and zeta potential.

As shown in Fig. 5, when adding $\mathrm{Ca}^{2+}$ to $\mathrm{CS}$ water, the residual turbidity decreased immediately from 25.5 NTU to 3.5 NTU. Turbidity then decreased slowly from 3.5 to 0.85 NTU during the next $30 \mathrm{~min}$. This determined that $\mathrm{Ca}^{2+}$ can affect the stability of $\mathrm{CS}$ immediately, lose stability, and regain stability in $30 \mathrm{~min}$. Concurrently, with the extension of time, the absolute value of zeta potential of CS continued to decrease and become stable after $30 \mathrm{~min}$. This was due to the carboxyl group in DCS ionizing and reacting with $\mathrm{Ca}^{2+}$ to form a non-ionizing interfering substance, thereby weakening the electronegativity of the surface of colloidal particles. This indicated that $\mathrm{Ca}^{2+}$ had a great effect on the stability of CS, and the CS was completely unstable and gained stability in $30 \mathrm{~min}$.

\section{Effects of $\mathrm{Ca}^{2+}$ and $\mathrm{Na}^{+}$Alone and Synergistic Action on the Stability of CS}

In Figs. 6 and 7, the inorganic electrolytes had a great influence on the stability of CS, with the residual turbidity of added $\mathrm{Ca}^{2+}$ decreasing more remarkably than $\mathrm{Na}^{+}$.
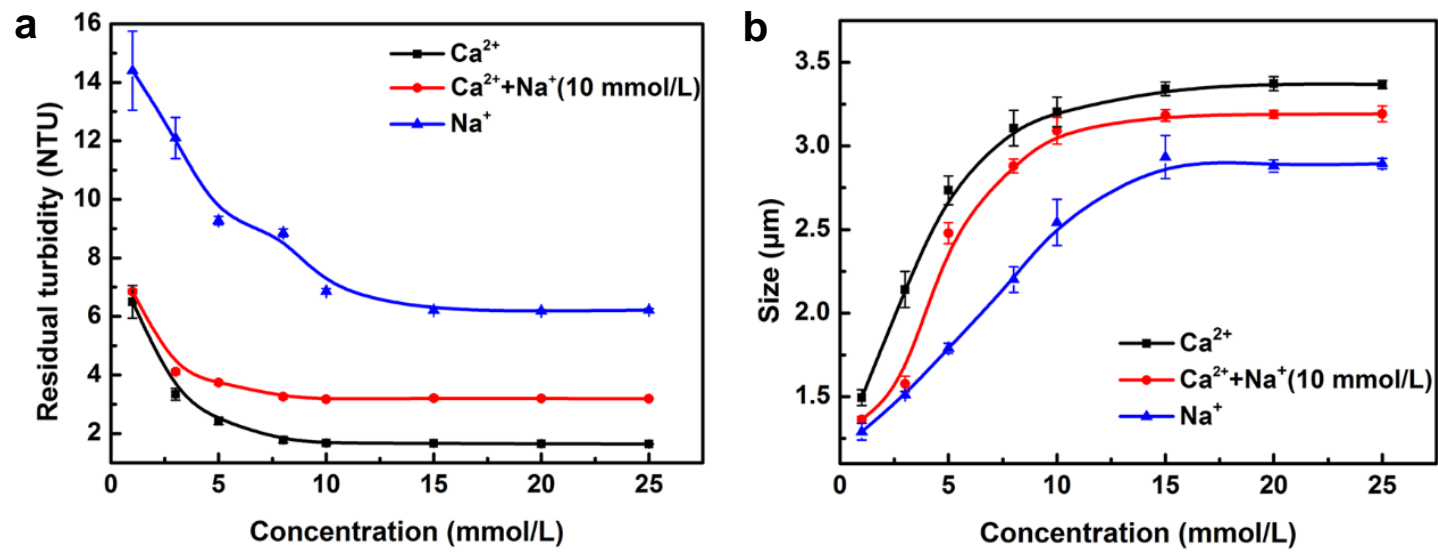

Fig. 6. Effects of inorganic electrolyte concentration on residual turbidity (a) and on size (b) (· $\mathrm{Na}^{+}$ was fixed at $10 \mathrm{mmol} / \mathrm{L}$, adding different $\mathrm{Ca}^{2+}$ )

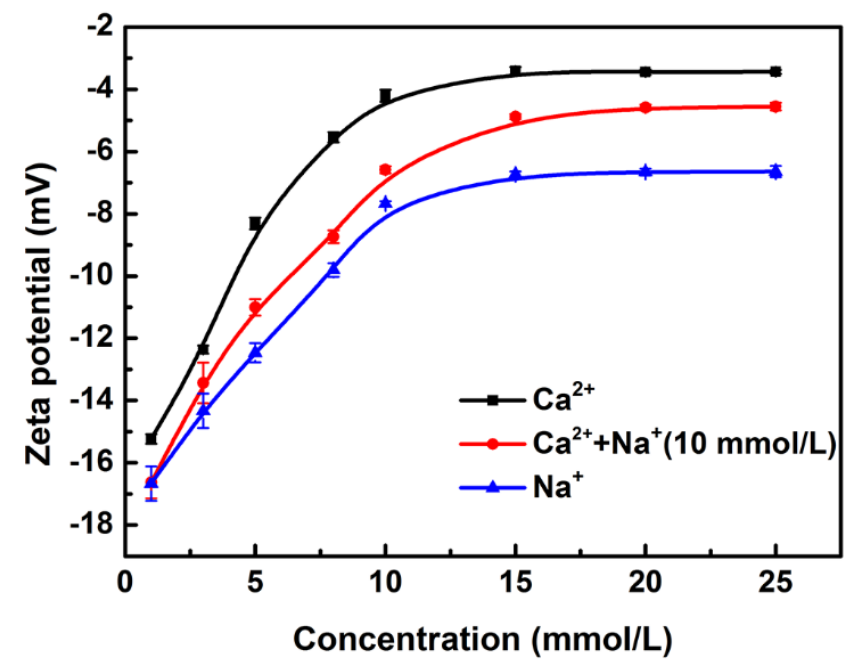

Fig. 7. Effects of inorganic electrolyte on zeta potential 
When metal ions were added, they would enter the electric double layer of colloidal particles through charge neutralization, thus the repulsive force between colloidal particles was reduced and it was easy to attract and aggregate with each other. This effect increases with the increase of the concentration of counter-ions (Verwey 1947). In addition, CS was noticeably negative and adsorbed with $\mathrm{Ca}^{2+}$ to balance a part of the electrical property. After the metal ions were pressed into the electric double layer, the charge reversed and the absolute value of zeta potential decreased, thus destabilizing the system (Bobacka et al. 1998; Stack et al. 2019).

The addition of $\mathrm{Na}^{+}$had little effect on the change of the average particle size of CS. This may have been because $\mathrm{Ca}^{2+}$ reacted with the resin in CS to form an insoluble viscous substance, while $\mathrm{Na}^{+}$only compressed the double-electron layer, making the colloidal particles easily aggregate into loose flocculation, it cannot be combined with CS to form viscous insoluble substances (Lee et al. 2012). Therefore, $\mathrm{Ca}^{2+}$ made colloid particle size change more prominent than $\mathrm{Na}^{+}$.

A surprising finding was that when $\mathrm{Ca}^{2+}$ and $\mathrm{Na}^{+}$were added together, the system instability was between the $\mathrm{Ca}^{2+}$ and $\mathrm{Na}^{+}$alone in Figs. 6 and 7. However, when the $\mathrm{Ca}^{2+}$ concentration reached $10 \mathrm{mmol} / \mathrm{L}$ and continued to rise, the turbidity, average particle size, and zeta potential of CS tended to be gentle and close to the effect of $\mathrm{Ca}^{2+}$ alone. This may have been due to the constant concentration of $\mathrm{Na}^{+}$in the solution, which was equivalent to acting as a "buffer" in the system (Chen 2016). In addition, there is competition between $\mathrm{Na}^{+}$and $\mathrm{Ca}^{2+}$ for adsorption sites. When the calcium ion forms a complex with a pair of carboxyl groups at a fiber surface, such complexation will have a greater contribution on colloidal instability. Such complexation would be discouraged by the presence of $\mathrm{Na}^{+}$.

\section{CONCLUSIONS}

1. The cationic demand and turbidity of DCS were mainly contributed by CS, while the electrical conductivity was mainly contributed by DS. Its sources were complex, including resin and lignin of the raw material itself, a variety of adhesives, fixatives, and fillers. There was a difference in the thermal stability of DCS and solids. The main weight loss substances of DCS were organic matter and inorganic salts, and the solids were mainly the weight loss of calcium carbonate during pyrolysis.

2. Both $\mathrm{Ca}^{2+}$ and $\mathrm{Na}^{+}$affect the stability of $\mathrm{CS}$, but $\mathrm{Ca}^{2+}$ was more likely to cause $\mathrm{CS}$ instability to produce flocculent precipitation, and the average particle size of CS increased. When $\mathrm{Ca}^{2+}$ and $\mathrm{Na}^{+}$were added together, the instability degree of the system was between $\mathrm{Ca}^{2+}$ and $\mathrm{Na}^{+}$addition alone. $\mathrm{Na}^{+}$appeared to play a "buffering" role.

\section{ACKNOWLEDGMENTS}

The authors are grateful for grants from the National Natural Science Foundation of China (21868004, 31660182), the Key Research and Development Plan of Guangxi Province (GuikeAB419259013), the Natural Science Foundation of Guangxi Province (2017GXNSFAA198200), and the Foundation of Key Laboratory of Pulp and Paper Science and Technology of Ministry of Education/Shandong Province of China (No. KF201819) that supported this research. 


\section{REFERENCES CITED}

Blanco, M. A., Negro, C., Gaspar, I., and Tijero, J. (1996). "Slime problems in the paper and board industry," Applied Microbiology \& Biotechnology 46(3), 203-208. DOI: $10.1007 / \mathrm{s} 002530050806$

Blanco Suárez, Á., Miranda Carreño, R., Negro Álvarez, C. M., García Suárez, C., Garcíaprol, M., and Sánchez, Á. (2007). "Full characterization of stickies in a newsprint mill: The need for a complementary approach," TAPPI Journal 35(3), 295302. DOI: $10.1385 /$ IR:35:3:295

Bobacka, V., Nasman, J., and Eklund, D. (1998). "Interactions between cationic starch and anionic trash of a peroxide-bleached TMP at different salt concentrations," Journal of Pulp and Paper Science 24(3), 78-81. DOI: 10.1007/s001070050285

Chen, C. (2016). "Aggregation process and mechanism of DCS interferent in papermaking white water circuit," Nanjing Forestry University, China.

Chen, C., Xu, H., Su, W., and Dai, H. (2014). "Separation and characterization of dissolved and colloidal substances from white water and study on their stability," Transaction of China Pulp and Paper 29(4), 23-29. DOI: 10.11981/j.issn.10006842.2014.04.23

Francis, D. W., and Ouchi, M. D. (2001). "Effect of dissolved and colloidal solids on newsprint properties," Journal of Pulp and Paper Science 27(9), 289-295.

Hubbe, M. A., Sundberg, A., Mocchiutti, P., Ni, Y. H., and Pelton, R. (2012). "Dissolved and colloidal substances (DCS) and the charge demand of papermaking process waters and suspensions: A review," BioResources 7(4), 6109-6193. DOI: 10.15376/biores.7.4.6109-6193

Jiang, B. F., Wen, Y., Li, Z., Xia, D., and Liu, X. (2018). "Theoretical analysis on the removal of cyclic volatile organic compounds by non-thermal plasma," Water Air \& Soil Pollution 229(2), Article number 35. DOI: 10.1007/s11270-018-3687-3

Jiang, Y. (2007). "Influence of papermaking system closure on paper properties," World Pulp \& Paper 5, 27-31. DOI:10.1007/s00226-005-0053-6

Johnsen, I. A., Lenes, M., and Magnusson, L. (2004). "Stabilization of colloidal wood resin by dissolved material from TMP and DIP," Nordic Pulp \& Paper Research Journal 19(1), 22-28. DOI: 10.3183/npprj-2004-19-01-p022-028

Lee, R., Stack, K., Richardson, D., Lewis, T., and Garnier, G. (2012). "Multi-salt coagulation of soft pitch colloids," Colloids and Surfaces a-Physicochemical and Engineering Aspects 409, 74-80. DOI: 10.1016/j.colsurfa.2012.06.005

Lee, R., Stack, K., Richardson, D., Lewis, T., and Garnier, G. (2012). "Effect of shear, temperature and $\mathrm{pH}$ on the dynamics of salt induced coagulation of wood resin colloids," Colloids and Surfaces a-Physicochemical and Engineering Aspects 396, 106-114. DOI: 10.1016/j.colsurfa.2011.12.049

Li, M. F., Li, G. X., Liu, Y., Jin, Y., Zhang, K. L., and Luo, L.-X. (2018). “Application of Fenton's reagent degrades dissolved and colloidal substances in old corrugated container white water," Nordic Pulp \& Paper Research Journal 33(3), 557-567. DOI: 10.1515/npprj-2018-3041

Li, X. F., Qin, M. H., Liu, N., and Miao, Q. X. (2008). "Study on dissolved and colloidal substances released during pulping of ONP," Second International Papermaking and Environment Conference, Proceeding, Books a and B, 23, 75-79.

Li, Z. Q. (2005). "Study on the mechanism of stickies deposition and its control in secondary fibers recycling," South China University of Technology, China. 
Liang, J. D., He, Y. L., Zhu, J. W., and Du, W. J. (2018). “Accumulation of dissolved and colloidal substances in water recycled during papermaking," Chemical Engineering Journal 168(2), 604-609. DOI: 10.1016/j.cej.2011.01.030

McLean, D. S., Stack, K. R., and Richardson, D. E. (2005). "The effect of wood extractives composition, $\mathrm{pH}$ and temperature on pitch deposition," Appita Journal 58(1), 52-55.

Miranda, R., Blanco, A., Negro, C., and Tijero, J. (2006). "Stickies removal in a deinking line of a newsprint mill: Efficiency of the different process stages," Cellulose Chemistry and Technology 40(9-10), 775-782. DOI: 10.1007/s10570-006-9063-2

Monte, M. C., Blanco, A., Negro, C., and Tijero, J. (2004). "Development of a methodology to predict sticky deposits due to the destabilisation of dissolved and colloidal material in papermaking - application to different systems," Chemical Engineering Journal 105(1-2), 21-29. DOI: 10.1016/j.cej.2004.07.013

Monte, M. C., Fuente, E., Blanco, A., and Negro, C. (2009). "Waste management from pulp and paper production in the European Union," Waste Management 29(1), 293 308. DOI: 10.1016/j.wasman.2008.02.002

Nurmi, M., Byskata, J., and Eklund, D. (2004). "On the interaction between cationic polyacrylamide and dissolved and colloidal substances in thermomechanical pulp," Paperi Ja Puu-Paper and Timber 86(2), 109-112. WOS: 000220311300011

Nylund, J., Olai, L., and Christer, E. (2007). "Character and stability of colloidal substances in a mechanical pulp suspension," Colloids and Surfaces A:

Physicochemical and Engineering Aspects 85(1), 81-87. DOI: 10.1016/09277757(94)02740-4

Rundlof, M., Sjolund, A. K., Strom, H., Asell, I., and Wågberg, L. (2000). "The effect of dissolved and colloidal substances released from TMP on the properties of TMP fines," Nordic Pulp \& Paper Research Journal 15(4), 256-265. DOI: 10.3183/npprj2000-15-04-p256-265

Rundlof, M., Eriksson, M., Strom, H., and Wågberg, L. (2002). "Effect of mannanase and lipase on the properties of colloidal wood extractives and their interaction with mechanical pulp fines," Cellulose 9(2), 127-137. DOI: 10.1023/a:1020143825530

Sarja, T. (2007). "Measurement, nature and removal of stickies in deinked pulp," University of Oulu, Finland.

Sousa, M. R., Lora-Garcia, S., and Lopez-Perez, J. (2018). "Modelling approach to an ultrafiltration process for the removal of dissolved and colloidal substances from treated wastewater for reuse in recycled paper manufacturing," Journal of Water Process Engineering 21, 96-106. DOI: 10.1016/j.jwpe.2017.11.017

Stack, K. R., Yaqoob, N., Ngwenya, E., Richardson, D. E., and Lewis, T. W. (2019). "Colloidal stability of Pinus radiata wood extractives Part 1: Effect of extractives composition and process variables," Appita 72(1), 15-29.

Su, W. P., Chen, C., Xu, H., Yang, W. S., and Dai, H. Q. (2016). "Filtering whitewater with an ultrafiltration membrane: effects of the interaction between dissolved organics and metal ions on membrane fouling," BioResources 11(1), 1108-1124. DOI: 10.15376/biores.11.1.1108-1124

Sundberg, A., Ekman, R., Holmbom, B., Sundberg, K., and Thornton, J. (1993). "Interactions between dissolved and colloidal substances and a cationic fixing agent in mechanical pulp suspensions," Nordic Pulp \& Paper Research Journal 8(1), 226231. DOI: $10.2113 / \mathrm{gsj}$ fr.14.2.142 
Tang, Y. N. (2018). "Analysis of the instability characteristics of microstickies and its effective purification in papermaking whitewater treated by enzyme," South China University of Technology, China.

Verwey, E. J. W. (1947). "Theory of the stability of lyophobic colloids," The Journal of Physical and Colloid Chemistry 51(3), 631-636. DOI: 10.1021/j150453a001

Wågberg, L., and Kolar, K. (2010). "Adsorption of cationic starch on fibres from mechanical pulps," Berichte der Bunsengesellschaft für physikalische Chemie 100(6), 984-993. DOI: 10.1002/bbpc. 19961000647

Wang, J. J. (2014). "Separation and analysis of interfering substances from papermaking white water," Nanjing Forestry University, China.

Wang, Z. W. (2013). "Measurement of the micro stickies in process waste paper recovery and research on their stability," South China University of Technology, China.

Wang Z. W., Li B., Wu S., B., and Lu P. (2012). "Physicochemical properties analysis and size distribution research of microstickies in whitewater," BioResources 7(4), 5794-5808. DOI: 10.15376/biores.7.4.5794-5808

$\mathrm{Xu}, \mathrm{Y}$. F., and Deng, Y. L. (2004). "The buildup of dissolved solids in closed white water systems," Tappi Journal 3(8), 17-2a1.

Yuan, C. F., Wang, W., Lin, Y., and Chen, Y. (2012). “A novel fuzzy comprehensive evaluation method for product configuration design integrated customer requirements," Journal of Computational \& Theoretical Nanoscience 6(1), 774-778. DOI: 10.1166/asl.2012.2256

Zhang, H. J., He, Z. B., Ni, Y. H., Hu, H. R., Zhou, and Y. J. (2007). "Characteristics of dissolved and colloidal substances in high yield pulp and their impact on filler retention," Appita Journal 60(5), 390-395. DOI: 10.1007/s00226-007-0133-X

Article submitted: May 25, 2020; Peer review completed: July 4, 2020; Revised version received and accepted: July 6, 2020; Published: July 10, 2020.

DOI: 10.15376/biores.15.3.6668-6679 